\title{
Occurrence of Permanent Changes in Vaginal and Uterine Epithelia in Mice Treated Neonatally with Progestin, Estrogen and Aromatizable or Non-Aromatizable Androgens
}

\author{
TAISEN IGUCHI AND NoBORU TAKASUGI \\ Department of Biology, Faculty of Science, Okayama University, \\ Tsushima, Okayama-shi 70O, Japan
}

\begin{abstract}
Synopsis
Female mice of the C57 Black/Tw strain were injected daily with $100 \mu \mathrm{g}$ testosterone, $50 \mu \mathrm{g}$ testosterone propionate (TP), $100 \mu \mathrm{g} 5 \alpha$-dihydrotestosterone (DHT) or $50 \mu \mathrm{g} 5 \alpha$-dihydrotestosterone propionate (DHTP), for 10 days from the day of birth. Two other groups of female mice were given neonatal injections with $20 \mu \mathrm{g}$ estradiol$17 \beta$ and $100 \mu \mathrm{g}$ progesterone for 10 days, respectively. All mice were ovariectomized at 60 days of age and killed at 90 days. In $100 \%$ of neonatally estrogenized or androgenized, ovariectomized mice, the cranial part of the vagina was lined with stratified epithelium with either cornification or parakeratosis or mucification. Stratification only or stratification with superficial squamous metaplasia or cornification took place in the uterine epithelia of $18 \%$ of the TP-treated, $75 \%$ of the DHT-treated and $50 \%$ of the DHTP-treated, ovariectomized mice. In contrast, neonatally estrogenized, ovariectomized mice did not show the estrogen-independent, persistent uterine changes. Neonatal progesterone treatment failed to induce the permanent changes in the vaginal and uterine epithelia.
\end{abstract}

Neonatal treatments of female mice with high doses of estrogenic or androgenic steroids induce estrogen-independent persistent proliferation and cornification of the vaginal epithelium, which is irreversible. Induction of the irreversible vaginal changes in mice depends on both the dose of the steroid administered neonatally and the age of the mice at the beginning of the treatment (Takasugi, 1963, 1964 and 1971; Kimura et al., 1967a and b; Mori, 1967 and 1969; Kohrman and Greenberg, 1968; Terenius et al., 1969; Shyamala et al., 1974; Iguchi et al., 1976; for review, see Takasugi 1976).

Vaginae of newborn mice which had been cultivated in a medium with estradiol$17 \beta$ exhibited estrogen-independent proliferation and cornification of the vaginal

Received for publication March 17, 1976. epithelium after being transplanted into syngeneic ovariectomized hosts. However, in newborn mouse vaginae cultivated in a medium with testosterone prior to the transplantation, neither proliferation nor cornification occurred in the epithelium after the transplantation (Kimura et al., 1967c). From this result, they suggested that testosterone in vivo might act on the vaginal epithelium as estrogen after its conversion to estradiol or a related steroid whereas estradiol acted directly on the epithelium. On the other hand, Ryan (1960) demonstrated that $5 \alpha$-reduced androgen could not be converted to estrogen by aromatizing enzyme. The present studies, therefore, were undertaken to examine whether sex steroids including aromatizable and non-aromatizable androgens had permanent effects on mouse vaginal and uterine 
epithelia when given neonatally.

\section{Materials and Methods}

Female mice of the C57 Black/Tw strain were used for the present experiments. The daily dose of $100 \mu \mathrm{g}$ progesterone $(\mathrm{P}), 20 \mu \mathrm{g}$ estradiol-17 $\beta$ (E), $100 \mu \mathrm{g}$ testosterone (T), $50 \mu \mathrm{g}$ testosterone propionate (TP), $100 \mu \mathrm{g} 5 \alpha$-dihydrotestosterone (DHT) or $50 \mu \mathrm{g} 5 \alpha$ dihydrotestosterone propionate (DHTP) dissolved in $0.02 \mathrm{~m} l$ sesame oil was subcutaneously injected into 6 groups of $6,7,10,11,9$ and 10 mice for 10 days starting on the day of birth, respectively. These steroids were purchased from Sigma Chemical Co., St. Louis except for DHTP which was purified and supplied by the laboratory of Teikoku Zoki Pharmaceutical Co., Tokyo. Another group of 9 mice given neonatal injections of $0.02 \mathrm{ml}$ sesame oil only for 10 days served as the controls.

All mice were ovariectomized at 60 days of age and killed 30 days thereafter. At autopsy, vaginae (including the lower part of cervix uteri and the inner part of vestibulum vaginae), uteri, clitorises (prepuce, cavernous body and os clitoridis if any) and submaxillary glands were weighed and fixed in Bouin's solution, and sectioned longitudinally and/or transversely in paraffin at $7 \mu \mathrm{m}$. The sections were stained with Delafield's hematoxylin and eosin.

\section{Results}

Vaginal changes in ovariectomized adult mice treated neonatally with various sex steroids

Vaginal opening occurred in mice which had been given neonatal $\mathrm{P}$ injections at $30-$
35 days of age as in the oil-injected controls. However, vaginae of mice given neonatal injections of T, TP, DHT or DHTP failed to form the orifice, whereas neonatally E-injected mice showed the vaginal opening at 1-3 days of age.

The vaginal epithelium in neonatally P-treated, ovariectomized adult mice was atrophic as that in the oil controls, consisting of 2 layers of cells (Fig. 1). Neither fusion nor common canal was formed between vagina and urethra in the P-treated mice. There was no significant difference in vaginal weight between the P-treated mice and the controls (Table 1).

Vaginae of 6 of 7 ovariectomized adult mice given neonatal $\mathrm{E}$ injections had markedly proliferated epithelia consisting of 10 15 layers of cornified or parakeratotic, granular, prickle and basal cells. In a remaining mouse, the superficial layer of the epithelium showed a mixture of cornified and mucous cells. In 4 of the estrogenized mice, a few small concretions were found in the vaginal lumen as reported by Takasugi and Bern (1962). The vaginal epithelium was connected with the urethral epithelium near the distal end, having common canal. These vaginae were considerably increased in weight (Table 1 , $\mathrm{p}<0.01)$.

In all ovariectomized adult mice given neonatal $\mathrm{T}$ injections, the fornico-cervical

Table 1. Organ weights in ovariectomized adult mice given neonatal injections of various sex steroids

\begin{tabular}{ccccccc}
\hline \hline \multirow{2}{*}{ Treatment } & \multirow{2}{*}{$\begin{array}{c}\text { No. of } \\
\text { mice }\end{array}$} & $\begin{array}{c}\text { Body } \\
\text { weight } \\
\end{array}$ & & \multicolumn{2}{c}{ Weights of organs $(\mathrm{mg}) / 20 \mathrm{~g}$ body weight } \\
\cline { 5 - 7 } & & & vagina & uterus & clitoris & $\begin{array}{c}\text { submaxillary } \\
\text { gland }\end{array}$ \\
\hline Oil & 9 & $23.2 \pm 0.91^{\dagger}$ & $20.1 \pm 1.01$ & $9.3 \pm 0.48$ & $8.4 \pm 0.62$ & $107.1 \pm 14.67$ \\
$100 \mu \mathrm{g} \mathrm{P}$ & 6 & $21.2 \pm 0.75$ & $21.5 \pm 1.67$ & $8.3 \pm 0.17$ & - & $116.9 \pm 7.42$ \\
$20 \mu \mathrm{g} \mathrm{E}$ & 7 & $18.1 \pm 0.71^{* *}$ & $41.9 \pm 4.22^{* *}$ & $12.8 \pm 1.16^{*}$ & - & $125.5 \pm 5.10$ \\
$100 \mu \mathrm{g} \mathrm{T}$ & 10 & $21.3 \pm 0.81$ & $26.1 \pm 3.25$ & $14.5 \pm 1.23^{* *}$ & $14.1 \pm 0.62^{* *}$ & $117.2 \pm 7.88$ \\
$50 \mu \mathrm{g} \mathrm{TP}$ & 11 & $23.3 \pm 0.88$ & $20.9 \pm 2.11$ & $11.3 \pm 0.95$ & $16.3 \pm 1.43^{* *}$ & $114.2 \pm 6.10$ \\
$100 \mu \mathrm{g}$ DHT & 9 & $21.3 \pm 0.58$ & $22.0 \pm 2.16$ & $14.7 \pm 2.08^{*}$ & $15.0 \pm 0.59^{* *}$ & $121.0 \pm 8.88$ \\
$50 \mu \mathrm{g}$ DHTP & 10 & $22.2 \pm 0.26$ & $24.3 \pm 2.10$ & $14.5 \pm 1.63^{* *}$ & $16.9 \pm 0.96^{* *}$ & $104.8 \pm 3.75$ \\
\hline
\end{tabular}

P: Progesterone E: Estradiol-17 $\beta \quad \mathrm{T}$ : Testosterone $\mathrm{TP}$ : Testosterone propionate

DHT : $5 \alpha$-Dihydrotestosterone DHTP : $5 \alpha$-Dihydrotestosterone propionate

$\dagger$ Mean \pm standard error $* 0.05>\mathrm{p}>0.01 * * \mathrm{p}<0.01$ ( $v$ s. Oil control, Student's $t$-test) 
region of the vaginal epithelium consisted of 3-7 layers of cells. The superficial layer of the cranial part of the epithelium (upper $3 / 5$ of vagina) was fully cornified in 7 of the $10 \mathrm{~T}$-treated mice, whereas the rest of the androgenized mice showed superficial parakeratosis in the epithelium (Table 2). However, the caudal part of the vaginal epithelium (lower $2 / 5$ of vagina) was composed of 3-5 layers of cells without cornification or parakeratosis.

The cranial part of the vaginal epithelium in all ovariectomized adult mice given neonatal TP injections consisted of 3-7 layers of cells with superficial cornification or parakeratosis. There were some highly mucified areas in the fornico-cervical region of the epithelium. The caudal part of the epithelium was composed of 4-7 layers of cells, showing neither cornification nor parakeratosis. One or two clumps of infiltrated lymphocytes were observed in this part of the connective tissue stroma.

In 4 of 9 ovariectomized adult females given neonatal injections of DHT, the cranial part of the vaginal epithelium was
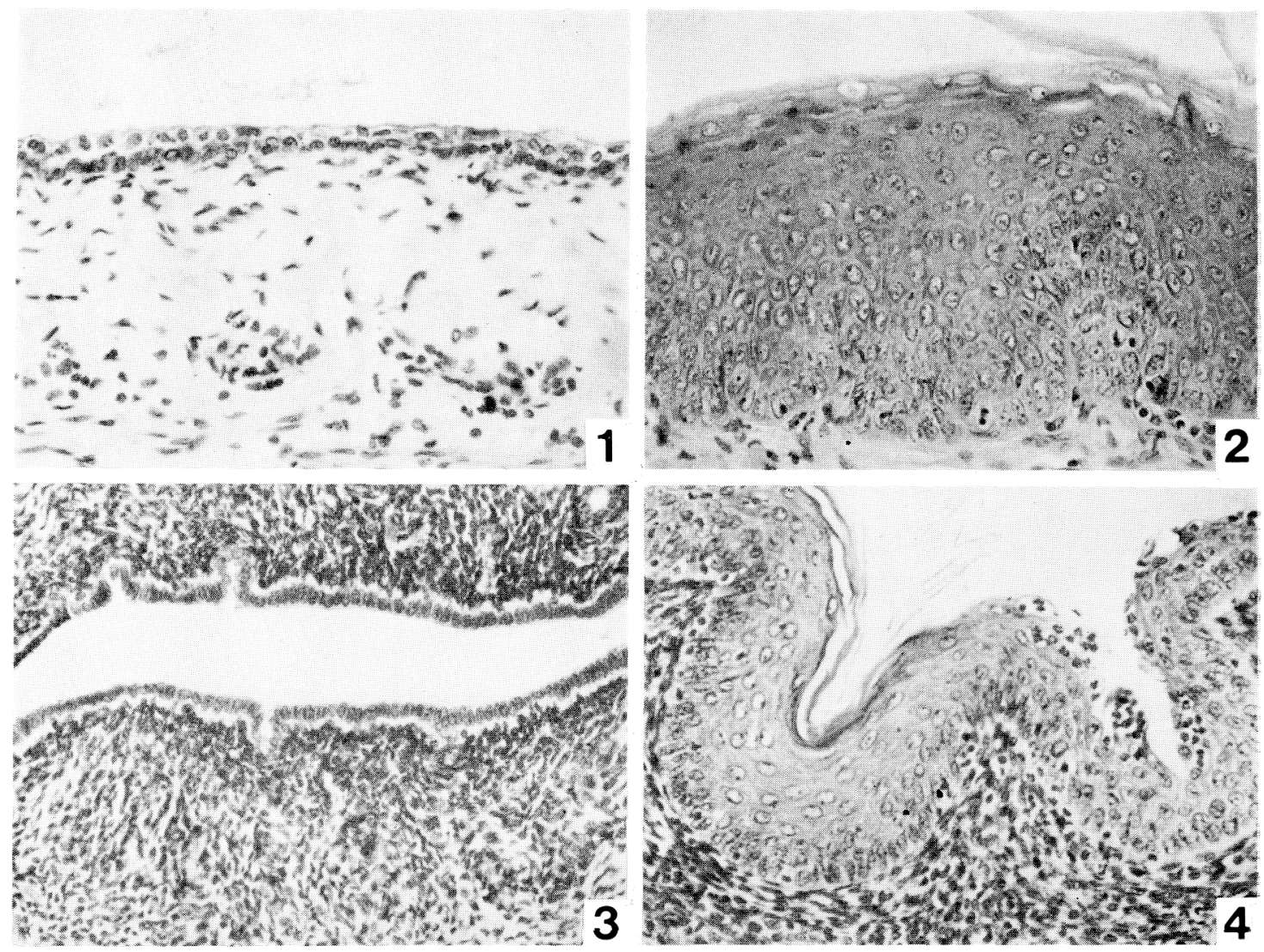

Fig. 1. Vagina of a 90-day-old, neonatally oil-injected, control mouse ovariectomized at 60 days of age. The epithelium is atrophic. $\times 260$.

Fig. 2. Vagina of a neonatally DHT-treated, 90-day-old mouse ovariectomized at 60 days of age. Note proliferation and cornification of the epithelium. $\times 260$.

Fig. 3. Uterus of a 90-day-old control mouse ovariectomized at 60 days of age. The epithelium is atrophic. $\times 260$.

Fig. 4. Uterus of a neonatally DHT-treated, 90-day-old mouse ovariectomized at 60 days of age. Note squamous stratification and partial cornification of the epithelium. $\times 260$. 
composed of the superficial cornified layer and 5-8 layers of prickle and basal cells. Vaginae of the other 5 animals had the 2 to 7-layered epithelium with superficial parakeratosis (Table 2, Fig. 2). In 3 of 9 mice of this group, infiltration of numerous leucocytes was observed both in the epithelium and the stroma. On the dorsal side of vagina, the caudal part of the epithelium consisted of 4-6 layers of cells, whereas the ventral wall was lined with 26 layers of cells resembling the urethral epithelial cells. In the caudal part of the vagina, neither cornification nor parakeratosis nor mucification was observed in the epithelium. The vaginal epithelium in the DHT-treated mice was connected with the urethral epithelium near the junction of the cranial and caudal parts, having a common lumen.

In 6 of 10 ovariectomized adult mice injected neonatally with DHTP, the cranial part of the vaginal epithelium was composed of 4-7 layers of cells with the superficial cornified layer. Vaginae of the other 3 mice had 3 to 6-layered epithelium, the superficial layer of which consisted of a mixture of cornified or mucified cells. The vagina of the remaining one was lined with the stratified epithelium having the superficial parakeratotic layer (Table 2). The caudal part of the epithelium was stratified, but neither cornified nor mucified. A common canal was formed between vagina and urethra, opening to the middle part of the vagina.

Vaginal weights in the groups of T-, TP-, DHT- and DHTP-treated mice were similar, as shown in Table 1. Hypospadia took place in all mice treated neonatally with E, T, TP, DHT and DHTP, except those with P.

Uterine changes in ovariectomized adult mice treated neonatally with various sex steroids

There was no significant difference in uterine weight between any two of the groups of neonatally T-, TP-, DHT- and DHTP-treated, ovariectomized adult mice, although the uteri of the T- and DHTPtreated mice were significantly heavier than those of the oil controls (Table $1, \mathrm{p}<0.01$ ).

The uterine epithelium in ovariectomized adult mice which had received neonatal $P$ injections consisted of a single layer of low columnar cells, being similar to that in the oil controls (Table 2, Fig. 3). Uteri of neonatally E-treated ovariectomized adult mice

Table 2. Permanent changes in vaginal and uterine epithelia in ovariectomized adult mice treated neonatally with sex steroids

\begin{tabular}{|c|c|c|c|c|c|}
\hline \multirow{2}{*}{ Treatment } & \multirow{2}{*}{$\begin{array}{l}\text { No. of } \\
\text { mice }\end{array}$} & \multicolumn{2}{|c|}{$\begin{array}{l}\text { No. of mice with the cranial part } \\
\text { of the vaginal epithelium showing }\end{array}$} & \multicolumn{2}{|c|}{$\begin{array}{c}\text { No. of mice with uterine epithelium } \\
\text { showing }\end{array}$} \\
\hline & & $\begin{array}{l}\text { cornification or } \\
\text { parakeratosis }\end{array}$ & atrophy & $\begin{array}{l}\text { stratification and/or } \\
\text { squamous metaplasia }\end{array}$ & atrophy \\
\hline A. Oil & 9 & 0 & 9 & 0 & 9 \\
\hline B. $\mathbf{P}$ & 6 & 0 & 6 & 0 & 6 \\
\hline C. $\mathrm{E}$ & 7 & 7 & 0 & 0 & 7 \\
\hline D. $\mathrm{T}$ & 10 & 10 & 0 & 0 & 10 \\
\hline E. TP & 11 & 11 & 0 & 2 & 9 \\
\hline F. DHT & $9^{*}$ & 9 & 0 & 6 & 2 \\
\hline G. DHTP & 10 & 10 & 0 & 5 & 5 \\
\hline \multirow{6}{*}{\multicolumn{2}{|c|}{$\begin{array}{l}\text { Fisher's exact } \\
\text { probability test }\end{array}$}} & \multicolumn{2}{|r|}{$\mathbf{P}$} & \multicolumn{2}{|r|}{$\mathrm{P}$} \\
\hline & & \multicolumn{2}{|c|}{$\mathrm{A}: \mathrm{C} \quad 0.0001$} & \multicolumn{2}{|c|}{$\mathrm{A}: \mathrm{E} \quad 0.289$} \\
\hline & & $A: 1$ & 0.0000 & \multicolumn{2}{|c|}{$\mathrm{A}: \mathrm{F} \quad 0.002$} \\
\hline & & A : & 0.0000 & \multicolumn{2}{|c|}{$A: G \quad 0.022$} \\
\hline & & A : $]$ & 0.0000 & \multicolumn{2}{|c|}{$D: F \quad 0.002$} \\
\hline & & $\mathrm{A}:$ & 0.0000 & \multicolumn{2}{|c|}{$\mathrm{E}: \mathrm{G} \quad 0.038$} \\
\hline
\end{tabular}

* One of 9 mice had infected uterus, which was excluded from the data. 
were slightly heavier than those of the oil controls $(0.01<\mathrm{p}<0.05)$, but the epithelium consisted of a single layer of atrophic cells as that in the oil controls (Tables 1,2).

In contrast, stratification with or without squamous metaplasia or cornification took place in the uterine epithelia of $18 \%$ of the TP-treated, $75 \%$ of the DHT-treated and $50 \%$ of the DHTP-treated, ovariectomized mice (Table 2, Fig. 4). Uteri of these androgenized mice occasionally showed a marked distension of their glands. Infiltration of lymphocytes was also occasionally observed in the stromal tissue.

Changes in clitoris and submaxillary gland in neonatally androgenized, ovariectomized adult mice

Neonatal injections of $\mathrm{T}, \mathrm{TP}, \mathrm{DHT}$ or DHTP caused clitoral enlargement in female mice (Table 1). An os clitoridis was formed by neonatal administration of any androgen used in this experiment as reported in rats previously (Glucksmann and Cherry, 1972). The clitoral enlargement persisted in all neonatally androgenized, ovariectomized adult mice. In the TP- and DHTP-treated mice, the clitorises showed preputial dehiscence at 15-17 days of age, which was caused by the parenchymal enlargement mostly due to the bone formation. This dehiscence persisted in these androgenized mice. An androgenic effect on the submaxillary gland was no longer discernible in all androgenized, ovariectomized adult mice.

\section{Discussion}

Kimura et al. (1967c) have suggested that the permanent vaginal changes in mice treated neonatally with androgen $(\mathrm{T})$ may be induced by estrogen which is produced by conversion of testosterone in vivo. The present studies demonstrated that, in mice, neonatal treatments with relatively high doses of estradiol, non-aromatizable andro- gens (DHT, DHTP) as well as aromatizable androgens ( $T, T P$ ) for 10 days resulted in estrogen-independent persistent proliferation with either cornification or parakeratosis or mucification in the vaginal epithelium. In neonatally androgenized mice, the superficial layer of the permanently proliferated vaginal epithelium consisted of cells undergoing cornification, parakeratosis or mucification, whereas permanent proliferation and cornification occurred uniformly in the epithelia of neonatally E-treated mice. Vaginae of the estrogenized, ovariectomized mice were heavier than those of the androgenized, ovariectomized females. The vaginal epithelium was much more proliferated in the former than in the latter. Accordingly, estradiol-17 $\beta$ seems to be most effective hormone in sex steroids used in the present experiments in inducing the permanent vaginal changes.

It has previously been reported that stratification and/or squamous metaplasia occasionally occur in the uterine epithelia of adult mice given neonatal injections of estrogen or androgen (Dunn and Green, 1963; Kimura and Nandi, 1967; Mori, 1968a, b and 1969). The present studies demonstrated that relatively high incidence of estrogenindependent, persistent stratification and/or squamous metaplasia took place in the uterine epithelia of ovariectomized adult mice given neonatal injections of TP, DHT or DHTP. However, neonatal administration of $\mathrm{T}$ or $\mathrm{E}$ failed to induce the permanent uterine changes.

Recent studies have revealed that $5 \alpha$ reduced androgen (DHT) is the active form of testosterone in some peripheral target organs (Anderson and Liao, 1968; Bruchovsky and Wilson, 1968; Liao and Fang, 1969; Williams-Ashman and Reddi, 1971). The present results indicate that $5 \alpha$-reduced, non-aromatizable androgens are more effective in inducing the permanent uterine changes than estrogen or aromatizable androgens. Accordingly, it is sug- 
gested that, in mice, neonatally administered $\mathrm{T}$ or TP can also act on the vagina and uterus after $5 \alpha$-reduction of the steroids in vivo in the induction of the permanent changes.

\section{Acknowledgements}

Purified $5 \alpha$-dihydrotestosterone propionate used in the present experiments was kindly given to the authors by Prof. K. Takewaki of Kawasaki Medical College who was supplied with the steroid through the courtesy of Drs. I. Chuman and H. Mori of Teikoku Zoki Pharmaceutical Co. The authors also wish to thank Dr. Y. Nishizuka and his colleagues of Aichi Cancer Center Research Institute for helpful consultation in the area of perinatal carcinogenesis. This work was supported by a Grant-inAid for Scientific Research from the Ministry of Education, Science and Culture of Japan given to N.T.

\section{References}

Anderson, K. M. and S. Liao (1968). Nature 219, 277.

Bruchovsky, N. and J. D. Wilson (1968). J. Biol. Chem. 243, 2012.

Dunn, T. B. and A. W. Green (1963). J. Nat. Cancer Inst. 31, 425.
Glucksmann, A. and C. P. Cherry (1972). J. Anat. $112,223$.

Iguchi, T., Y. Ohta and N. Takasugi (1976). Develop. Growth Different. 18, 59.

Kimura, T. and S. Nandi (1967). J. Nat. Cancer Inst. 39, 75.

Kimura, T., S. L. Basu and S. Nandi (1967a). $J$. Exp. Zool. 165, 71.

Kimura, T., S. Nandi and K. B. DeOme (1967b). Ibid. 165, 211.

Kimura, T., S. L. Basu and S. Nandi (1967c). Ibid. $165,497$.

Kohrman, A. F. and R. E. Greenberg (1968). Devel. Biol. 18, 632.

Liao, S. and S. Fang (1969). Vitamins and Hormones $27,17$.

Mori, T. (1967). Annot. Zool. Japon. 40, 82.

Mori, T. (1968a). Ibid. 41, 43.

Mori, T. (1968b). Ibid. 41, 85.

Mori, T. (1969). Proc. Japan Acad. 45, 791.

Ryan, K. J. (1960). Acta Endocr. 35, 697.

Shyamala, G., T. Mori and H. A. Bern (1974). J. Endocr. 63, 275.

Takasugi, N. (1963). Endocrinology 72, 607.

Takasugi, N. (1964). J. Fac. Sci. Univ. Tokyo 11, 397.

Takasugi, N. (1971). Proc. Japan Acad. 47, 193.

Takasugi, N. (1976). Internat. Rev. Cytol. 44, 193.

Takasugi, N. and H. A. Bern (1962). Proc. Soc. Exp. Biol. Med. 109, 622.

Terenius, L., B. J. Meyerson and A. Palis (1969). Acta Endocr. 62, 671.

Williams-Ashman, H. G. and A. H. Reddi (1971). Annual Rev. Physiol. 33, 31. 